Saudi Journal of Oral and Dental Research

Abbreviated Key Title: Saudi J Oral Dent Res

ISSN 2518-1300 (Print) |ISSN 2518-1297 (Online)

Scholars Middle East Publishers, Dubai, United Arab Emirates

Journal homepage: https://saudijournals.com/sjodr

Case Report

\title{
Full Mouth Rehabilitation - Reestablishing Smile- A Case Report
}

Dr. Ponjayanthi $V^{1 *}$, Dr. Femin David ${ }^{1}$, Dr. T. Sreelal ${ }^{2}$, Dr. Aparna Mohan ${ }^{3}$, Dr. T. C Giri ${ }^{3}$, Dr. Allen Jim Hines ${ }^{3}$

${ }^{1}$ P.G Student, Department of Prosthodontics, Sree Mookambika Institute of Dental Sciences, Kulasekaram, Kanyakumari, Tamilnadu, India

${ }^{2}$ Professor and Head of the Department, Department of Prosthodontics, Sree Mookambika Institute of Dental Sciences, Kulasekaram, Kanyakumari,

Tamilnadu, India

${ }^{3}$ Readers, Department of Prosthodontics, Sree Mookambika Institute of Dental Sciences, Kulasekaram, Kanyakumari, Tamilnadu, India

DOI: $10.36348 /$ sjodr.2020.v05i03.012

| Received: 19.03.2020 | Accepted: 27.03.2020 | Published: 30.03.2020

*Corresponding author: Dr. Ponjayanthi V

Abstract

Full mouth rehabilitation always requires meticulous treatment planning and careful attention for procedures. All the efforts are directed towards reestablishing a state of functional efficiency in which, the teeth and their periodontal structures, the muscles of mastication and temporomandibular joint mechanisms are all functions together in synchronous harmony. This clinical report describes the oral rehabilitation of a patient with multiple missing and decayed teeth. The specific treatment objective being restoration of masticatory function, esthetic rehabilitation and improved self confidence.

Keywords: Broadrick occlusal plane analyzer, full arch rehabilitation, cast partial denture, functional efficiency.

Copyright @ 2020: This is an open-access article distributed under the terms of the Creative Commons Attribution license which permits unrestricted use, distribution, and reproduction in any medium for non-commercial use (NonCommercial, or CC-BY-NC) provided the original author and source are credited.

\section{INTRODUCTION}

The term full mouth rehabilitation is used to indicate extensive and intensive restorative procedures in which the occlusal plane is modified in many aspects in order to accomplish equilibrium. It is indicated in restoration of multiple missing teeth, improperly designed bridge work, to correct developmental defect and occlusal rehabilitation. According to previous study the prevalence of missing teeth was about $45.5 \%$ between the age group of 6 to 74 years [1]. Hence restoring the missing teeth with permanent prosthesis is important to alleviate further complications and restore the functions of stomatognathic system.

\section{CASE REPORT}

A 51 year old female patient reported to the department of Prosthodontics, crown \& bridge, Sree Mookambika Institute of Dental Sciences, Kulasekharam, complaining of difficulty in chewing and uncomfortable to smile in front of public due to compromised esthetics. The patient's expectations were to improve esthetics along with functionality. Her past medical history was noncontributory. TMJ showed no clicking or pain and intraoral examination was done (Fig-1) that revealed:

Missing teeth: 15,16,25,35,36,37,46,47. Discoloured filling in 11,21 . Radiographic examination revealed root canal treated teeth: $11,12,13,17,21,23,26,27$.

\section{PROCEDURE}

1. In the first phase of treatment complete maxillary and mandibular full arch impression was made using irreversible hydrocolloid impression material and diagnostic cast was obtained.

2. Followed by which facebow transfer was done (Fig-2) for recording the craniomaxillary relationship and cast is then mounted in a semiadjustale articulator using an interocclusal record.

3. Then occlusal plane was established with the help of Broadrick occlusal plane analyzer.

4. The condylar guidance is modified with by using centric and eccentric records.

5. Diagnostic tooth preparation was done in the mounted cast and diagnostic wax up was done using mockup wax (Fig-3).

6. As the patient had sufficient interocclusal distance and no loss of facial height the vertical dimension was not altered.

After completing the initial diagnostic phase the treatment plan was drawn to restore esthetics and function and all the treatment options including differences in costs, the level of tooth structure removal, expected clinical longevity, the time period necessary to conclude the treatment and possible esthetic results 
were explained to the patient. Due to socioeconomic constrains the patient opted for ceramic facing full arch fixed partial denture in the maxillary arch and cast partial denture in the mandibular arch.

1. Followed by this, tooth preparation for ceramic facing crown done in relation to 17,14,13,12,11,21,22,23,24,26,27 (Fig-4).

2. Final impression was made with polyvinyl siloxane impression material and cast was poured with type IV gypsum.

3. Interoccusal record was then made using jet bite material (polyvinyl siloxane based) because of its dimensional stability [2] and the cast is mounted in semiadjuatable articulator using this record.

4. Silicone putty indices of the diagnostic wax up was utilized to restore the prepared teeth with autopolymerising acrylic resin temporary (Fig-5) using indirect-direct method [3]. Temporary full arch prosthesis was then cemented using non eugenol cement (Fig-6).

5. Maxillary full arch metal framework was fabricated and trial was done (Fig-7).

6. Then followed by bisque trial was done along with wax trial of the cast partial denture.

7. Final finishing and polishing of the prosthesis is done and inserted in patient's mouth (Fig-8).

Oral hygiene instructions were given and patient was recalled after one month for review. All the objectives of treatment planning were achieved and patient was fully satisfied with the treatment.
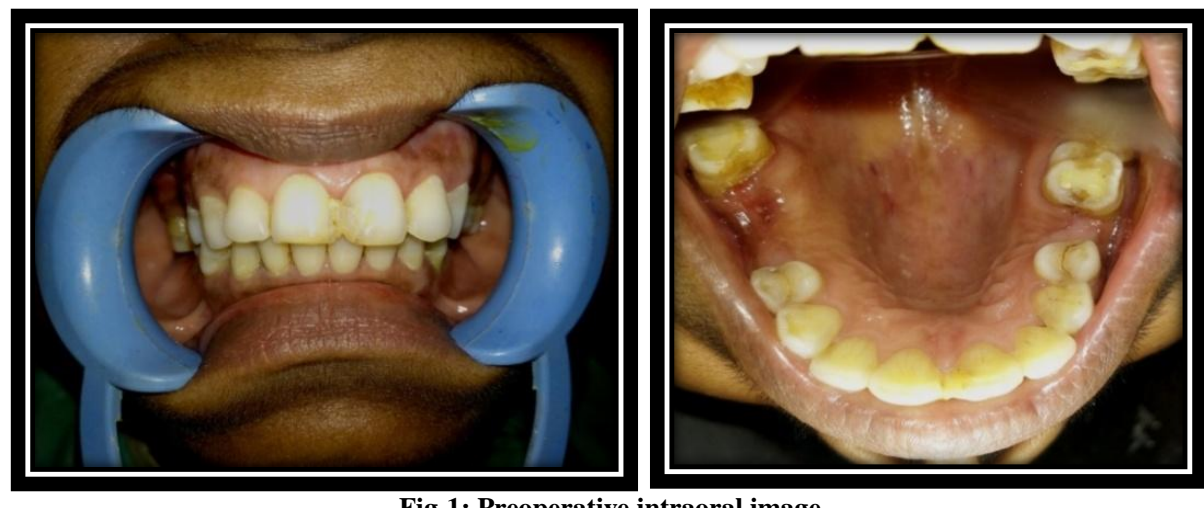

Fig-1: Preoperative intraoral image

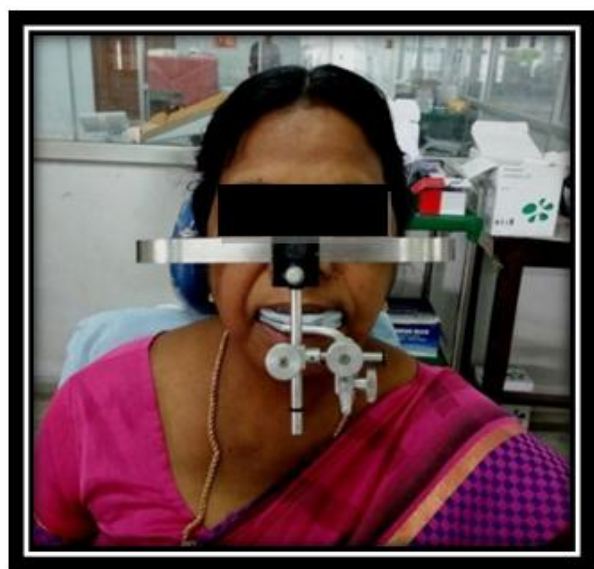

Fig-2: Facebow transfer

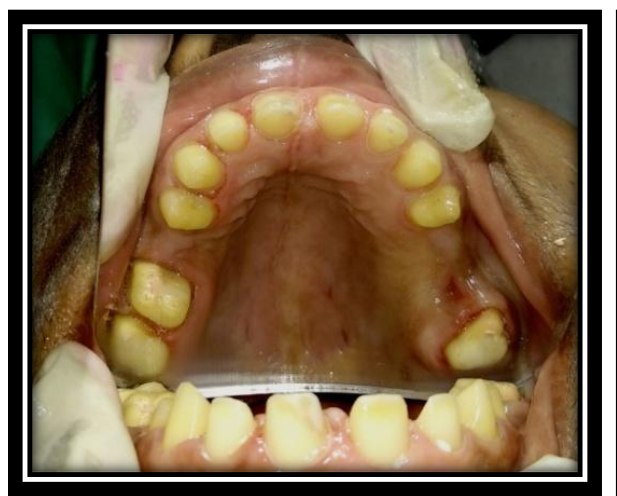

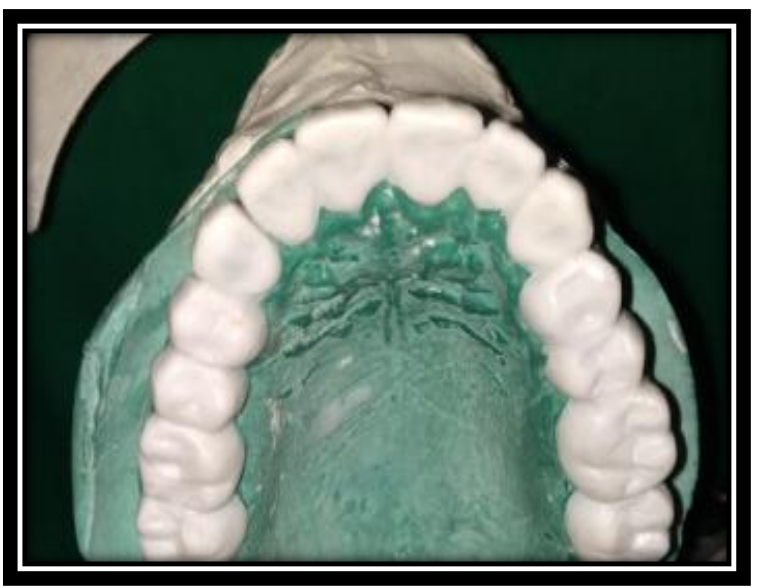

Fig-3: Mock waxup

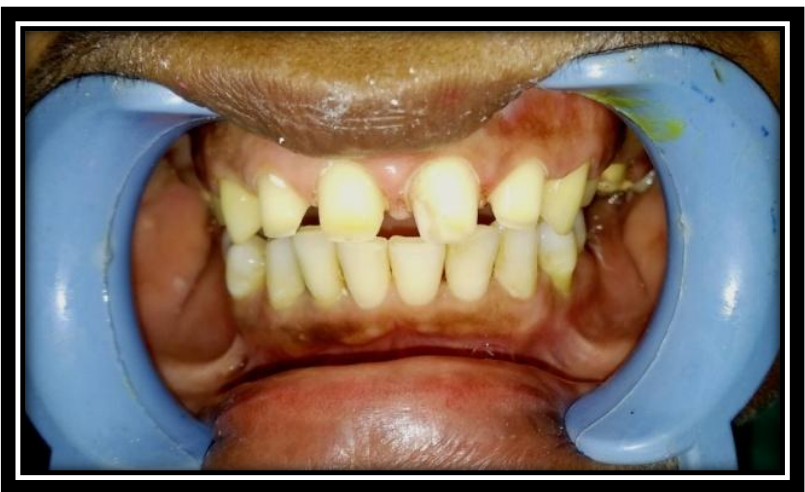

Fig-4: Tooth preparation 

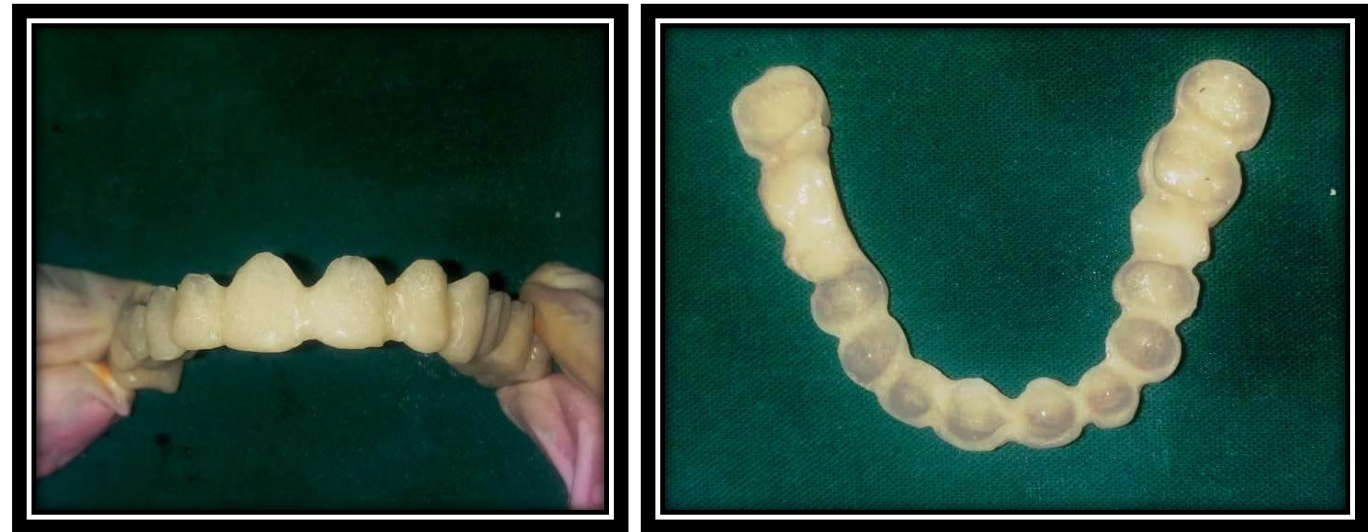

Fig-5: Maxillary full arch temporary

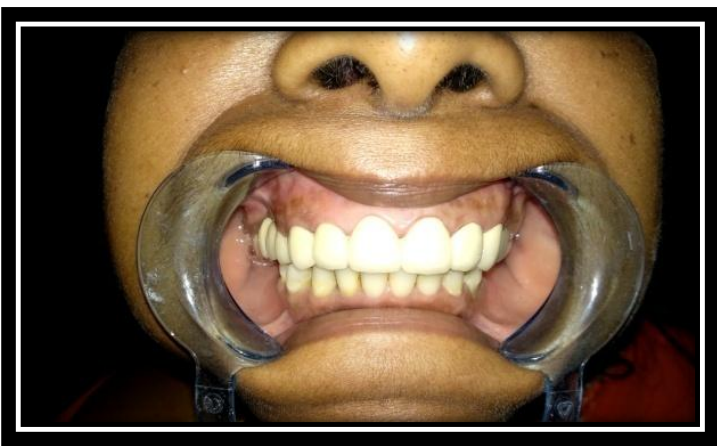

Fig-6: Temporary crown intraoral image

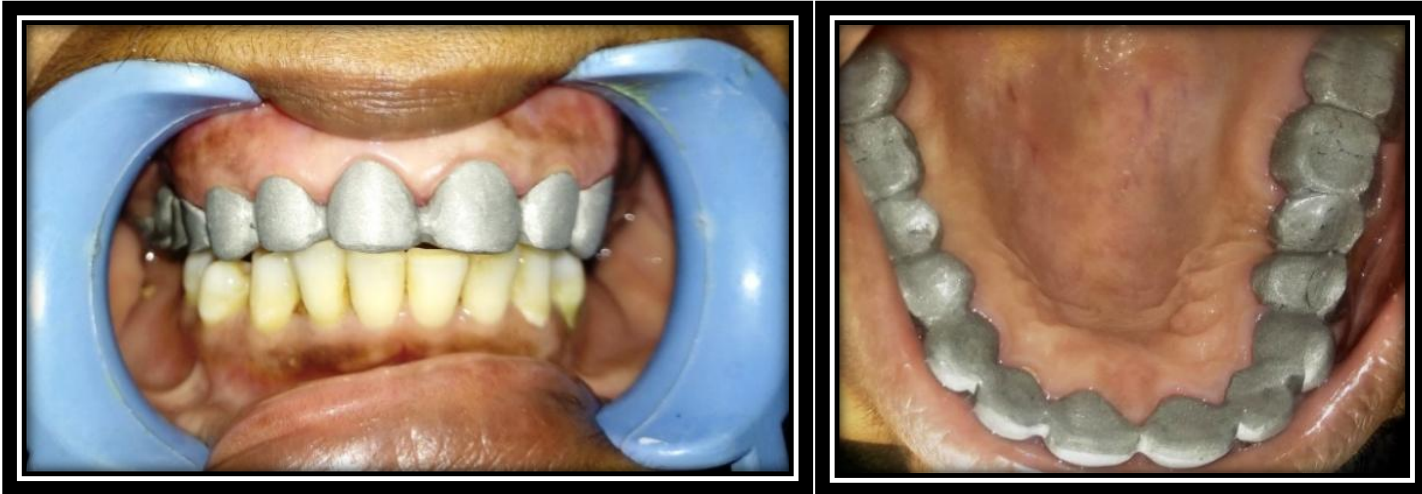

Fig-7: Metal trial
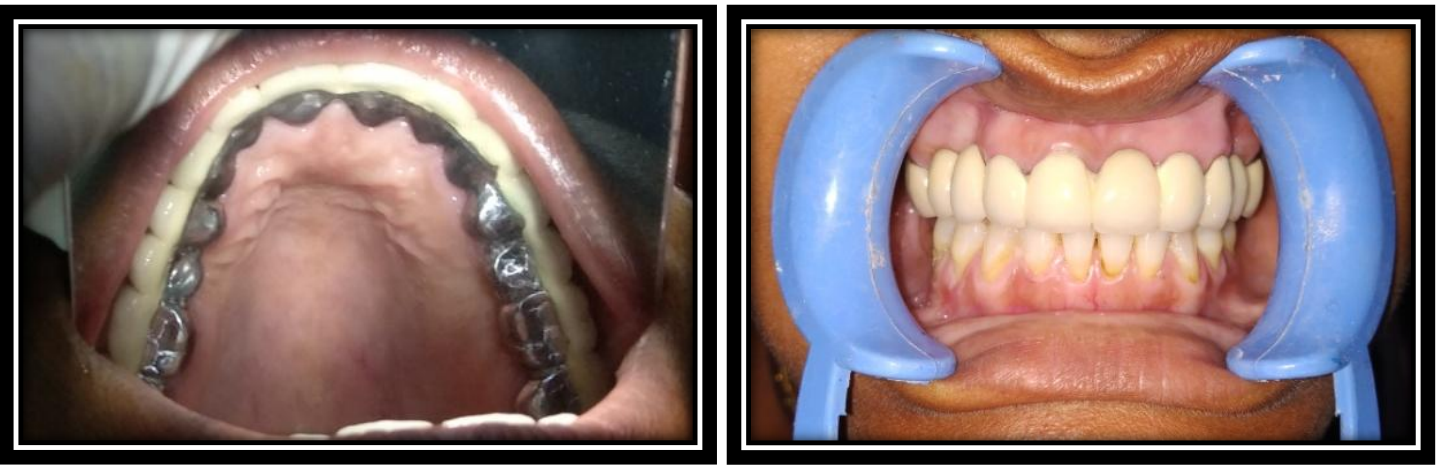

Fig-8: Final prosthesis intraoral image

\section{DISCUSSION}

Edentulism is a common oral condition and it is unavoidable. Early intervention is strongly recommended to prevent residual ridge resorption and further complications such as supraeruption of the opposing dentition which alters the occlusal plane, impaired masticatory function, compromised esthetics and function which also affect the patient's quality of 
life [4]. Lack of evidence regarding the long term outcomes of treatment materials and methods causes difficulty in clinical decision making [5]. Initial facebow transfer and diagnostic waxup was done to accomplish several treatment objectives, including determination of incisal guidance, determining the amount of tooth structure removal needed and to verify esthetics and functional modification needed [6]. For long term function and prognosis, conventional treatment modality that includes occlusal plane analysis and modification, tooth preparation with immediate provisionals and definitive ceramic facing prosthesis (which reduce the wear of opposing teeth) was chosen for the patient. The objective of establishing good esthetics and function was accomplished with this method.

\section{CONCLUSION}

There is an ever increase in the rate of edentulism with increase in age of general population. The quantity of life is increased with improved medical facility, but the quality of life can be improved by restoring the form and function with the primary concern being esthetics. In this case report, a successful full mouth rehabilitation of a patient with multiple missing and decayed teeth restored with maxillary full arch fixed partial denture and mandibular titanium cast partial denture was discussed.

Post treatment counseling and follow-up are essential to motivate the patient to maintain a healthy lifestyle for extended positive prognosis [7].

\section{REFERENCES}

1. George, B., John, J., Saravanan, S., \& Arumugham, I. M. (2011). Pattern of permanent tooth loss among children and adults in a suburban area of Chennai. AOSR, 1, 72-78.

2. Tejo, S. K., Kumar, A. G., Kattimani, V. S., Desai, P. D., \& Nalla, S. (2012). A comparative evaluation of dimensional stability of three types of interocclusal recording materials-an in-vitro multi-centre study. Head \& face medicine, $8(1)$, 27.

3. Regish, K. M., Sharma, D., \& Prithviraj, D. R. (2011). Techniques of fabrication of provisional restoration: an overview. International journal of dentistry, 2011;1-5.

4. Emami, E., de Souza, R. F., Kabawat, M., \& Feine, J. S. (2013). The impact of edentulism on oral and general health. International journal of dentistry, 2013:1-7.

5. Johansson, A., Johansson, A. K., Omar, R., \& Carlsson, G. E. (2008). Rehabilitation of the worn dentition. Journal of oral rehabilitation, 35(7), 548-566.

6. Simon, H., \& Magne, P. (2008). Clinically based diagnostic wax-up for optimal esthetics: the diagnostic mock-up. Journal of the California dental association, 36(5), 355-362.

7. AlShahrani, M. T., Haralur, S. B., \& Alqarni, M. (2017). Restorative rehabilitation of a patient with dental erosion. Case reports in dentistry, 2017:1-6. 